\title{
Médiévales
}

Langues, Textes, Histoire

69 | automne 2015

Travailler à Paris (XIIIe-XVIe siècle)

\section{Leonie V. HICKS et Elma BRENNER éd., Society and Culture in Medieval Rouen. 911-1300}

Turnhout, Brepols, 2013, 400 p. (« Studies in the Early Middle Ages », 39)

\section{Élisabeth Lalou}

\section{OpenEdition}

Journals

Édition électronique

URL : https://journals.openedition.org/medievales/7663

DOI : 10.4000/medievales.7663

ISSN : 1777-5892

Éditeur

Presses universitaires de Vincennes

Édition imprimée

Date de publication : 30 novembre 2015

Pagination : 210-212

ISBN : 978-2-84292-444-7

ISSN : 0751-2708

Référence électronique

Élisabeth Lalou, "Leonie V. Hicks et Elma brenner éd., Society and Culture in Medieval Rouen. 971-1300 », Médiévales [En ligne], 69 | automne 2015, mis en ligne le 12 décembre 2015, consulté le 24 avril 2022. URL : http://journals.openedition.org/medievales/7663; DOI : https://doi.org/10.4000/medievales. 7663

Ce document a été généré automatiquement le 24 avril 2022.

Tous droits réservés 


\title{
Leonie V. HICKS et Elma BRENNER éd., Society and Culture in Medieval Rouen. 911-1300
}

Turnhout, Brepols, 2013, 400 p. («Studies in the Early Middle Ages », 39)

\author{
Élisabeth Lalou
}

\section{RÉFÉRENCE}

L. V. HICKS et E. BRENNER éd., Society and Culture in Medieval Rouen. 911-1300, Turnhout, Brepols, 2013, 400 p. («Studies in the Early Middle Ages »,39)

1 Ce nouveau livre, Société et culture dans le Rouen médiéval. 911-1300, regroupe douze contributions de chercheurs anglo-saxons et français qui représentent le renouveau de la recherche sur la ville de Rouen au Moyen Âge. Alors que les villes de Caen (Laurence Jean-Marie), Lisieux et Bayeux (François Neveux) et les "petites villes » (Bruno Sintic) ont trouvé leurs historiens, l'historiographie rouennaise s'était comme assoupie, après la production d'études très importantes sur la draperie normande (Jean-Louis Roch), la construction et les métiers de Rouen (Philippe Lardin) ou le tabellionage rouennais. Les fouilles de la cathédrale ont donné lieu à plusieurs articles importants (Jacques Le Maho, Cécile Niel). Vincent Tabbagh a traité du personnel ecclésiastique et Norman Golb des juifs de Rouen. Monuments, maisons et églises ont bénéficié d'études. Mais il reste encore beaucoup à faire. Cet ouvrage donne des pistes.

2 L'importance de la ville de Rouen, «capitale» du duché de Normandie, ville extrêmement peuplée, à l'activité économique majeure, n'est plus à démontrer. Le livre étudie l'évolution de la société et du milieu culturel entre le $\mathrm{x}^{\mathrm{e}}$ et le XIV ${ }^{\mathrm{e}}$ siècle. Son titre est d'ailleurs un peu partiel, car plus de la moitié des contributions s'intéressent à l'espace de la ville, sujet très neuf, qui bénéficie des avancées de la cartographie en même temps que des approches anthropologiques. 
3 La problématique de l'espace est déclinée en plusieurs articles. Le développement urbain de Rouen (Bernard Gauthiez) est étudié en trois phases : autour de 1000 et le $\mathrm{XI}^{\mathrm{e}}$ siècle (extension du Portus au Burgus, avec un premier pont sur la Seine); 1050-1204 (construction d'une nouvelle muraille, au tracé contesté par les historiens et archéologues, dont l'avis est présenté plus loin dans l'ouvrage) ; 1204-1330 (croissance de l'espace urbain et construction d'un nouveau paysage architectural: château de Philippe Auguste, reconstruction de la cathédrale, lotissements de maisons pour les ouvriers de la laine, évolution des murailles et don des fossés sans plus d'utilité pour les pauvres). La ville devait compter au XIV ${ }^{\mathrm{e}}$ siècle entre 50000 et 60000 habitants dans et hors les murs qui entouraient alors 200 hectares (quand, en 1150, les murs englobaient 50 hectares, contre 40 hectares à Paris).

4 À cette description de l'évolution du paysage matériel de la ville, il faut ajouter l'étude des rues et des paroisses. Leonie V. Hicks s'essaye à saisir, dans les récits des chroniqueurs, le « mouvement et l'espace de Rouen » à travers les rues de la ville. Elle prête attention à la situation de Rouen au $\mathrm{x}^{\mathrm{e}}$ siècle face aux voisins proches ou lointains. Elle étudie aussi les révoltes comme celle de 1090 menée par Conan, fils de Gilbert Pilate contre Robert Courteheuse ou la rébellion dans la cathédrale en 1119, souvenir peut-être de révoltes contre la réforme de l'Église en des temps plus anciens. La description du paysage autour de Rouen depuis le haut de la tour ducale est célèbre : "quam pulchram [...] patriam». Les récits des processions, des mariages ou enterrements (la mort de Guillaume en 1087), ainsi que des entrées (celle d'Henri I ${ }^{\text {er }}$ en 1107) ou des translations de reliques (celles de saint Romain par Guillaume Bonne Ame), fournissent des informations sur l'espace des rues. Il ne faut pas oublier le paysage sonore de la ville : cris, chansons, cloches (il y aurait eu un combat de cloches entre la cathédrale, l'abbaye de Saint-Amand et Saint-Ouen).

5 La structure de plusieurs paroisses rouennaises a été étudiée par Philippe Cailleux. On pourrait penser naïvement que l'archevêque a depuis toujours les droits sur les paroisses de la ville. Or, c'est au contraire l'aboutissement d'un long processus décrit par Grégory Combalbert : les abbayes bénédictines implantées dans la ville jouissaient jusqu'en 1130 de droits sur la plupart des paroisses de Rouen; un des exemples est l'église Saint-Paul où étaient installées des religieuses dépendant de Montivilliers. Les archevêques tentèrent de s'emparer des droits sur les églises tout au long du XII siècle, jusqu'à en arriver parfois à des actes de violence, comme pour l'église de Saint-Candele-Vieux (1198). Pour Saint-Paul, le procès entre les abbesses de Montivilliers et l'archevêque dura fort longtemps, de même que celui avec Saint-Ouen. Pierre de Collemezzo et Eudes Rigaud s'impliquèrent dans cette volonté d'imposer le jus episcopalis dans les paroisses de Rouen. Cette action fut menée aussi à Saint-Wandrille contre l'abbaye qui affirmait ses droits sur quatre paroisses proches de l'abbaye.

6 Pour comprendre la ville médiévale, il faut aussi étudier les représentations mentales que pouvaient s'en faire les habitants. Une thèse en cours à l'Université de Rouen étudie, dans cette veine, l'« Espace réel, [l']espace perçu à Rouen $d u x^{e}$ au xve siècle : le rôle des communautés religieuses dans la fabrique de la ville médiévale" (Lise Levieux). Ce présent ouvrage replace Rouen dans sa relation à un plus vaste espace : Rouen est en effet une des " capitales » de "l'empire plantagenêt ». La notion même de capitale est étudiée à plusieurs reprises : par Bernard Gauthiez, qui propose un plan des centres de pouvoir à Rouen à la fin du XII ${ }^{e}$ siècle, mais surtout par Fanny Madeline qui, par l'étude des itinéraires des rois Henri II, Richard ${ }^{\mathrm{er}}$ et Jean, montre l'évolution de 
leur relation à la capitale de la Normandie. Le mot de " capitale » figure dans le titre de l'article de Paul Webster qui revient sur les relations de «king John" avec Rouen. L'article de Fanny Madeline est très important parce qu'il replace la ville de Rouen dans le réseau de résidences ducales - plus tard adoptées par les Capétiens. Elle met en valeur l'importance du mode de vie itinérant de ces souverains dans leur relation à l'espace et à leur politique de construction. Rouen ne peut être considérée en effet isolément, mais comme appartenant à un groupe de résidences situées à proximité les unes des autres : la villa de Quevilly, le prieuré grandmontain de Notre-Dame du Parc ou, plus éloignées, La Roche Orival, Les Andelys, Le Vaudreuil ou le château de Lyons. Il est possible, grâce à des cartes très parlantes, de comprendre l'évolution de la politique de Henri II et de ses fils.

7 Rouen est donc bien la capitale du duché et, pour ces trois souverains, un lieu de résidence privilégié. Ils ne se rendent que beaucoup plus rarement à Caen, pourtant autre centre de pouvoir important depuis Guillaume. Rouen serait donc une des capitales de l'« empire », à côté de Londres ou de Poitiers, dont une carte dessine les murailles au XII ${ }^{\mathrm{e}}$ siècle. La ville de Rouen fut comparée à la ville de Rome, capitale de l'empire romain, dans le poème Rothoma nobilis dont Elisabeth Van Houts propose l'édition. Ce poème, daté de 1148, évoque le règne de Geoffroy et de Mathilde, qualifiée d'« imperialis conjunx». La dénomination d'« empire » pour désigner le vaste espace plantagenêt trouve une légitimité dans la comparaison avec la ville de Rome.

8 La société urbaine de Rouen fait l'objet, dans ce livre, d'une étude très complète. À côté du duc, l'archevêque de Rouen est, avec l'abbé de Saint-Ouen, le pouvoir le plus important dans la ville. La carrière de Robert, archevêque de Rouen de 989 à 1037, est l'objet d'une étude détaillée. Rouen est alors une ville riche. L'archevêque s'applique à reconstituer le temporel de la cathédrale, qu'il reconstruit peut-être. Il rassemble autour de lui des clercs érudits, se constitue une bibliothèque dont il reste un manuscrit conservé aujourd'hui à la Bibliothèque municipale de Rouen (Y7).

Outre l'archevêque et son clergé, les abbés, moines et moniales, la société urbaine fonctionne dans un effort pour stabiliser la relation entre bourgeoisie et aristocratie. Les bourgeois de Rouen jouissent d'une certaine célébrité dès le XII ${ }^{e}$ siècle. Les grandes familles de marchands - les Du Donjon, Val Richer, du Chastel, Trentegerons ou Malpalu - dirigent la ville: c'est l'organisation urbaine décrite dans les fameux Établissements de Rouen, délivrés par Henri II. La liste des maires de Rouen de 1171 à 1246 est fournie par Manon Six. Leur fortune provient, d'une part, d'opérations financières et de l'usure (même si la présence de banquiers proprement dits n'est pas facile à distinguer dans les sources) et, de l'autre, de leur implication dans l'administration ducale puis royale. La présence d'une aristocratie urbaine est moins connue (Daniel Power). Les bourgeois imitent leur mode de vie : ils se font construire des maisons de pierre ou graver un sceau. La morgue aristocratique se fait sentir : chef des rebelles en 1090, Conan est un bourgeois face aux chevaliers qui répriment le mouvement. Les chanoines sont majoritairement issus de familles aristocratiques. Mais des liens se tissent, de plus en plus nombreux, entre ces classes sociales. Les aristocrates épousent des filles de la bourgeoisie; ils partagent l'exercice du pouvoir et la présence de l'aristocratie est sensible dans l'économie urbaine: on les voit impliqués dans le commerce du vin ou emprunter aux juifs.

La présence des juifs à Rouen est assez bien documentée (Elma Brenner et Leonie V. Hicks). L'actuelle «rue aux juifs» rend compte encore aujourd'hui de l'existence de 
leur quartier - dévasté par les bombardements de la deuxième guerre. La découverte d'un bâtiment juif sous le palais de justice alimente encore aujourd'hui la controverse sur son utilisation (synagogue, école ou maison particulière ?). La présence à Rouen d'un centre intellectuel important est probable, mais n'est pas aussi connue que celui de Troyes. Un premier massacre eut lieu en 1096, au moment du départ des croisés. Puis le XIII siècle imposa aux juifs de Rouen comme à ceux du royaume de France les décisions de Louis IX, hostile à leur présence. Le bûcher d'un hérétique en 1253 pourrait être l'écho de conversions forcées. L'expulsion de 1306 vit partir de Rouen l'essentiel de cette population : maisons, synagogues et autres bâtiments furent saisis et enregistrés par les commissaires royaux aux questions juives.

11 Bourgeois, aristocrates et juifs habitaient dans leur majorité intra muros, à proximité de la cathédrale. En revanche les malades et les pauvres furent en partie repoussés hors de la ville, à l'écart, surtout les lépreux dans la léproserie de Mont-aux-Malades à laquelle les ducs, depuis Henri $\mathrm{I}^{\mathrm{er}}$, firent des dons. Les femmes lépreuses étaient recueillies à la Salle aux Puelles fondée entre 1185 et 1188 par Henri II, qui leur donna des maisons et bâtiments, distraits de sa résidence à Quevilly. Les malades étaient logés à La Madeleine, fondée au $\mathrm{XI}^{\mathrm{e}}$ siècle, probablement par l'archevêque et les chanoines, au nord de la cathédrale. Outre ces fondations, les ducs organisaient l'aumône aux pauvres. Henri II et, au début du XIII ${ }^{\mathrm{e}}$ siècle, les Capétiens firent des dons aux pauvres, pour leur bâtir des maisons. Guillaume de Saane, trésorier de la cathédrale, fonda un hôpital pour les pauvres pèlerins, qui fut plus tard gratifié par Philippe IV le Bel. Le même Guillaume de Saane fonda aussi à Paris le Collège du trésorier pour les étudiants du diocèse de Rouen. Richesse acquise par le commerce et aumônes sont liées. Un exemple en est intéressant: plus tard, lorsque les marchands étrangers devaient obtenir des lettres de hanse pour pouvoir exercer leur marchandise à Rouen, la municipalité utilisait l'argent qu'elle en tirait pour faire l'aumône aux pauvres. Une " pauvre femme » reçut ainsi, en 1390, 60 sous pour « nourrir ses sept petits enfants ».

Ce n'est ici qu'une petite partie de ce que nous apporte ce beau livre qui explore les espaces urbains dans toutes leurs acceptions, monumentales, festives, culturelles et sociales. 